\title{
Inclement weather forces stopovers and prevents migratory progress for obligate soaring migrants
}

\author{
Julie M. Mallon ${ }^{1 *}$, Keith L. Bildstein² and William F. Fagan'
}

\begin{abstract}
Background: Migrating birds experience weather conditions that change with time, which affect their decision to stop or resume migration. Soaring migrants are especially sensitive to changing weather conditions because they rely on the availability of environmental updrafts to subsidize flight. The timescale that local weather conditions change over is on the order of hours, while stopovers are studied at the daily scale, creating a temporal mismatch.

Methods: We used GPS satellite tracking data from four migratory Turkey Vulture (Cathartes aura) populations, paired with local weather data, to determine if the decision to stopover by migrating Turkey Vultures was in response to changing local weather conditions. We analyzed 174 migrations of 34 individuals from 2006 to 2019 and identified 589 stopovers based on variance of first passage times. We also investigated if the extent of movement activity correlated with average weather conditions experienced during a stopover, and report general patterns of stopover use by Turkey Vultures between seasons and across populations.

Results: Stopover duration ranged from $2 \mathrm{~h}$ to more than 11 days, with $51 \%$ of stopovers lasting $<24 \mathrm{~h}$. Turkey Vultures began stopovers immediately in response to changes in weather variables that did not favor thermal soaring (e.g., increasing precipitation fraction and decreasing thermal updraft velocity) and their departure from stopovers was associated with improvements in weather that favored thermal development. During stopovers, proportion of activity was negatively associated with precipitation but was positively associated with temperature and thermal updraft velocity.

Conclusions: The rapid response of migrating Turkey Vultures to changing weather conditions indicates weatheravoidance is one of the major functions of their stopover use. During stopovers, however, the positive relationship between proportion of movement activity and conditions that promote thermal development suggests not all stopovers are used for weather-avoidance. Our results show that birds are capable of responding rapidly to their environment; therefore, for studies interested in external drivers of weather-related stopovers, it is essential that stopovers be identified at fine temporal scales.
\end{abstract}

Keywords: Flight behavior, Fly-and-forage, Raptors, Cathartidae, Energy minimization, Soaring, Track annotation

\footnotetext{
* Correspondence: jmmallon@umd.edu

'Department of Biology, University of Maryland, College Park, MD 20742, USA

Full list of author information is available at the end of the article
}

(c) The Author(s). 2021 Open Access This article is licensed under a Creative Commons Attribution 4.0 International License, which permits use, sharing, adaptation, distribution and reproduction in any medium or format, as long as you give appropriate credit to the original author(s) and the source, provide a link to the Creative Commons licence, and indicate if changes were made. The images or other third party material in this article are included in the article's Creative Commons licence, unless indicated otherwise in a credit line to the material. If material is not included in the article's Creative Commons licence and your intended use is not permitted by statutory regulation or exceeds the permitted use, you will need to obtain permission directly from the copyright holder. To view a copy of this licence, visit http://creativecommons.org/licenses/by/4.0/. The Creative Commons Public Domain Dedication waiver (http://creativecommons.org/publicdomain/zero/1.0/) applies to the data made available in this article, unless otherwise stated in a credit line to the data. 


\section{Background}

As birds migrate, they pass through a variety of habitats and experience variable environmental conditions. Local weather conditions in these habitats change with time, which influence the flight behavior of migrants, especially the likelihood of suspending and resuming active migration [1, 2]. Passerines avoid departing stopovers during precipitation [3] and are more likely to resume active migration during low wind speeds and decreasing surface pressure [4]. Migratory raptors also avoid migrating during poor weather conditions; they are rarely observed migrating during cold fronts but are observed in peak numbers immediately following a passing cold front $[5,6]$. Similarly, the likelihood of terrestrial soaring birds stopping over increases on days with cloud cover and rain [7] and when thermal updraft strength is weak (sensu [8]).

Soaring birds are especially sensitive to changing weather conditions because they rely on the availability of environmental updrafts to subsidize flight. Although terrestrial birds can soar using orographic updrafts [9] or turbulence [10] to subsidize flight, thermals [8] are the most important type of updraft for most soaring migrants because thermals are widely distributed across the landscape [11], allow birds to reach altitudes necessary for fast cross-country soaring, and allow for straight, efficient flight paths [12]. Thermals (i.e., vortices of ascending hot air surrounded by descending cooler air) $[11,13]$ are generated by differential heating of the earth's surface. Thermals are, therefore, an uncertain resource that only form under appropriate weather conditions [9, 13]. Poor weather conditions slow or prevent the development of updrafts, thereby forcing birds to switch to energetically expensive flapping flight $[14,15]$ or grounding them.

Despite recognizing the relationship between migratory flight behavior and changing weather conditions, stopover use by large, soaring birds has been understudied. This is in part due to challenges around defining what constitutes a stopover - rule selection varies depending on the species ecology and desired behavior. Some of the definitions of stopovers for raptors include: $\leq 150 \mathrm{~km} /$ day [16], < $100 \mathrm{~km} /$ day [17, 18], < $50 \mathrm{~km} /$ day of directed flight [19], $\leq 25 \mathrm{~km} /$ day [20], $>24 \mathrm{~h}$ in an area $<30 \mathrm{~km}$ in diameter [21], and spending more than $24 \mathrm{~h}$ in an area [22]. These definitions pose two problems. First, all of these definitions consider the durations of stopovers to be $\geq 24 \mathrm{~h}$, due in part to the assumption that stopovers are used primarily to refuel. If we define stopovers based on the movement behavior of individuals, however, stopovers occur whenever individuals do not engage in fast, directed flight but are otherwise expected to do so. Using this movement-based definition of stopovers, the duration of stopovers may be much shorter than $24 \mathrm{~h}$ as local weather conditions can change rapidly and may only prevent birds from flying for short periods of time (i.e., hours). Clearly, standardized measures that constitute what are and are not stopovers are warranted.

Stopover behavior is ideal to study using Turkey Vultures (Cathartes aura) because they are obligate soaring migrants [23] and cannot sustain themselves aloft for long periods using flapping flight [24]. Hence, Turkey Vultures should be sensitive to changes in weather and stop frequently to avoid poor weather conditions. Here we investigate if stopovers used by Turkey Vultures are linked to changes in weather conditions that are poor for thermal soaring. To this end, we used satellite tracking data from four migratory Turkey Vulture populations, paired with local weather data. As a first step, we identified stopovers using first passage time (FPT) [25]. We automated identification of stopovers by selecting the radius and FPT threshold based on the structure of the data to avoid under- and over-selection of stopovers. We explored general patterns of stopover use by comparing the frequencies of stopover use between seasons and across populations.

Next, we evaluated when Turkey Vultures began their stopovers, relative to changing local weather conditions. As obligate scavengers, Turkey Vultures have several behavioral and physiological adaptations to minimize energetic costs [10, 26, 27]. We hypothesized that, to further minimize energetic costs, Turkey Vultures should fly as long as weather conditions allow for energy-efficient soaring flight and would stop as soon as weather conditions deteriorate, rather than switch to flapping flight $[28,29]$. Last, we evaluated if average weather conditions experienced by Turkey Vultures also affected their general movement activity during stopovers.

\section{Methods \\ Study species}

We used GPS-GSM tracking data collected between 2006 and 2019 from four migratory populations that represent three of the seven subspecies of Turkey Vulture (C. aura aura, C. aura meridionalis, and C. aura ruficollis). These populations range across most of the species' distribution - from Canada to southern South America (Supplemental Fig. 1). Tracking data were provided by Hawk Mountain Sanctuary (Pennsylvania, USA) and accessed via Movebank [30].

\section{Weather predictors}

We accessed weather data using Movebank Env-data annotation [31]. We selected weather variables that were known to either be important for thermal soaring and orographic soaring or were related to inclement weather (Supplemental Table 1). To focus on the behavioral 
response of Turkey Vultures to changing weather conditions, we excluded any static variables (e.g. NDVI, landcover).

\section{Stopover classification}

We used only migrations with regularly collected data (i.e., mean data interval $<3 \mathrm{~h}$ ). We annotated migrations from continuous tracks using first passage time (FPT; $\mathrm{R}$ package adehabitatLT) [32] and manually reviewed each migration for precision of start and end dates. FPT measures the time it takes an individual to leave a circle of a given radius, which informs about an individual's behavioral state. Short FPTs indicate straight, fast movements such as commuting between habitats [33] or migration [34]. Long FPTs indicate localized movements such as foraging [25, 33, 35], residency [34], or resting [35].

For the purposes of annotating stopover locations, we linearly interpolated any spatiotemporal gaps within the movement trajectories to get hourly fixes. To find which days potentially included stopovers using FPT, we first selected the radius that maximized log-variance of FPT (between 2500 and $6000 \mathrm{~m}$ ) for each migration. We selected this range of radii based on patterns of activity and inactivity in our dataset, which accounted for different movement speeds among populations and between seasons.

We anticipated some stopovers may be quite short because Turkey Vultures are diurnal migrants. For example, if weather fronts moved in during the late afternoon (i.e., flight hours) and passed overnight (i.e., roosting hours) a Turkey Vulture may stopover, ceasing flight before their normal roosting hours, but such a stopover is likely to go undetected by normal estimates [16-22]. Therefore, we chose to be highly conservative with our selection of stopovers and identified the start and end of stopovers at the hourly scale.

To find the start and end times of each stopover, we used a threshold relative to the variance of the FPT for each migration; this reduced under-selection of stopovers from tracks with high FPT variance and overselection of stopovers from tracks with low FPT variance. Stopovers selected from FPT were rejected if < $25 \%$ of the data were during daylight hours or if the duration was $<2 \mathrm{~h}$. To find non-stationary stopovers that were missed with this approach, we considered groups of $>30$ points within a $15 \mathrm{~km}$ buffer to be a 'stopover' (where the mean duration of 30 points in our dataset is $41 \pm 10 \mathrm{~h}$ ). To improve the precision of the start and end times of stopovers in our dataset, we removed the first and last observations if those speeds exceeded $95 \%$ of all the speeds during the stopover. If an individual ceased activity during normal roosting hours (approx. 1700-0800 h), we considered 0800 the following morning to be the start of the stopover.

\section{Analysis}

To determine if there was a difference in the frequency of stopover use among populations or between seasons, we used a linear mixed model. The response variable was the total number of stopovers per migration, the fixed effects were population, season, and the interaction of population and season, and the random effect was individual id.

To determine if Turkey Vultures used stopovers in response to changes in weather at the species level, we plotted the average hourly changes for each weather variable. As not all stopovers were expected to be in response to weather, we sought to remove noise from the dataset by first ranking stopovers by their proportion of activity. Proportion of activity, or the proportion of daytime hours where there was flight activity, was calculated for non-roosting hours, which were determined by local sunrise and sunset times. To ensure the movement activity represented flight activity, rather than geolocation errors, we defined activity as $>1 \mathrm{~km} / \mathrm{h}$. To avoid including stopovers used for feeding, we excluded the most active third of stopovers from our dataset $(n=189)$ for these analyses. We subset each weather variable from $7 \mathrm{~h}$ before to $7 \mathrm{~h}$ after the start of each stopover. We selected a $14 \mathrm{~h}$ window to avoid signals related to normal diurnal patterns in weather, while also capturing the full range of flight hours of a diurnal migrant. To facilitate comparison across populations with different climates and across years, we used the hourly change of each weather parameter as our response variables. For each hour, we calculated the rate of change across all stopovers. To account for uneven numbers of stopovers among individuals, we averaged these hourly values to the individual level. For each variable, we used a loess smoother to visually inspect the average rate of change over time relative to the start of stopovers. We then determined if the start of stopovers lagged relative to the minima and maxima for each weather variable. To determine if the decision to depart from stopovers lagged relative to changing environmental conditions, we repeated this analysis for the end of stopovers. We report the population-specific responses to changing weather variables at the start and end of stopovers in the Supplementary materials.

To compare movement behavior during stopovers, we used proportion of activity as the response variable. To evaluate the effect of mean weather conditions during a stopover on movement behavior, we used a binomial generalized linear mixed model (GLMM) to identify if any weather variables were associated with daytime movement during stopovers. Our response variable was the proportion of active hours out of the number of daytime hours during the stopover. We used only stopovers with complete weather data $(n=460)$ and used the mean 
of each weather variable (Supplemental Table 1) during the stopover as a predictor in our full model. We removed any predictors with correlations $>0.6$, retaining the predictor that we expected to be the most ecologically relevant. We included individuals nested within population as our random effect. All analyses were done using $\mathrm{R}$ version 4.0.2 [36].

\section{Results}

\section{Description of stopover use}

We analyzed 174 migrations of 34 individuals from 2006 to 2019 and identified 589 stopovers. Frequency of stopover use varied among populations and between seasons (Table 1). Regardless of season, the Central Canada population used stopovers most frequently $(\beta=6.159$, $\mathrm{SE}=0.967, \mathrm{t}=6.372$; Supplemental materials). All populations except Western Canada used stopovers more frequently during fall migration than during spring migration $(\beta=1.938, \mathrm{SE}=1.000, \mathrm{t}=1.938$; Supplemental materials).

Movement behavior during stopovers varied from highly sedentary to highly tortuous (Fig. 1). Total distances moved during stops ranged from 0 to $601 \mathrm{~km}$. Duration of stopovers ranged from $2 \mathrm{~h}$ to more than 11 days. $51 \%$ of stopovers $(n=300)$ were $<24 \mathrm{~h}$ in duration. $58 \%$ of stopovers $(n=$ 342) started or ended on a day where birds migrated $>$ $100 \mathrm{~km}$. All stopovers $>24 \mathrm{~h}(n=289)$ had at least one stopover day where the bird travelled a total distance $<100 \mathrm{~km}$. Of these, $90 \%(n=260)$ had at least one stopover day where the bird travelled a total distance $<25 \mathrm{~km}$.

\section{Onset of stopovers}

Stopovers typically began in the midafternoon (Supplemental Fig. 2). At the species-level, the beginning of stopovers temporally matched the peak rate of change of precipitation fraction (Fig. 2). Several weather variables (Supplemental Table 1) had peak rates of change within one to two hours of the start of stopovers, including downward shortwave radiation, sensible heat flux, thermal updraft velocity, and total atmospheric water (Fig. 2).

There was no predictable response to change in surface pressure or orographic updraft velocity. Other weather variables showed no peak in the rate of change but a gradual change over time, including boundary height, temperature, and wind speed. Responses were similar across all populations (Supplemental materials).

\section{Departure from stopovers}

Stopovers typically ended in the early morning (Supplemental Fig. 2). At the species-level, Turkey Vultures showed a response to fewer weather variables when departing stopovers and resuming migration (Fig. 3). Stopover departures were delayed relative to the peak rate of change of thermal updraft velocity but temporally matched the peak rates of change for temperature and boundary height. In contrast, the rate of change in downward shortwave thermal radiation peaked more than one hour after the end of stopovers.

Departure from stopovers also followed decreases in the rate of change of precipitation fraction and sensible heat flux. There was no predictable response to change in orographic updraft velocity, total atmospheric water, surface pressure, or wind speed. Responses were similar across three of four populations; however, the Western Canada population departed from stopovers during increasing rates of precipitation (Supplemental Fig. 4c).

\section{Movement behavior during stopovers}

Movement behavior during stopovers was associated with weather conditions that promoted thermal soaring

Table 1 Seasonal differences in stopover use among populations. We report the total, mean, and standard error of the number of stopovers used by each population and during each migration season. As stopover use is expected to vary as a function of migration distance, we report the mean and standard error of migration distance per stopover used

\begin{tabular}{|c|c|c|c|c|c|c|}
\hline Season & Population & Individuals & $\begin{array}{l}\text { Total number of } \\
\text { migrations }\end{array}$ & $\begin{array}{l}\text { Total number of } \\
\text { stopovers }\end{array}$ & $\begin{array}{l}\text { Number of stopovers per } \\
\text { migration (mean } \pm \mathrm{se} \text { ) }\end{array}$ & $\begin{array}{l}\text { Migration distance }(\mathrm{km}, \\
\text { mean } \pm \mathrm{se})\end{array}$ \\
\hline \multirow[t]{4}{*}{ Spring } & Southwest USA & 14 & 39 & 44 & $1.1 \pm 0.2$ & $2690 \pm 163.6$ \\
\hline & Central Canada & 6 & 19 & 128 & $6.7 \pm 0.7$ & $1409 \pm 297.2$ \\
\hline & Western Canada & 6 & 11 & 32 & $2.9 \pm 0.4$ & $1371 \pm 220.3$ \\
\hline & $\begin{array}{l}\text { Southern South } \\
\text { America }\end{array}$ & 4 & 11 & 22 & $2.0 \pm 0.5$ & $1735 \pm 232.3$ \\
\hline \multirow[t]{4}{*}{ Fall } & Southwest USA & 14 & 45 & 102 & $2.3 \pm 0.3$ & $1996 \pm 171.9$ \\
\hline & Central Canada & 8 & 23 & 188 & $8.2 \pm 0.9$ & $960 \pm 105.7$ \\
\hline & Western Canada & 6 & 11 & 22 & $2.0 \pm 0.6$ & $2187 \pm 283.9$ \\
\hline & $\begin{array}{l}\text { Southern South } \\
\text { America }\end{array}$ & 5 & 15 & 51 & $3.4 \pm 0.7$ & $1382 \pm 212.8$ \\
\hline
\end{tabular}




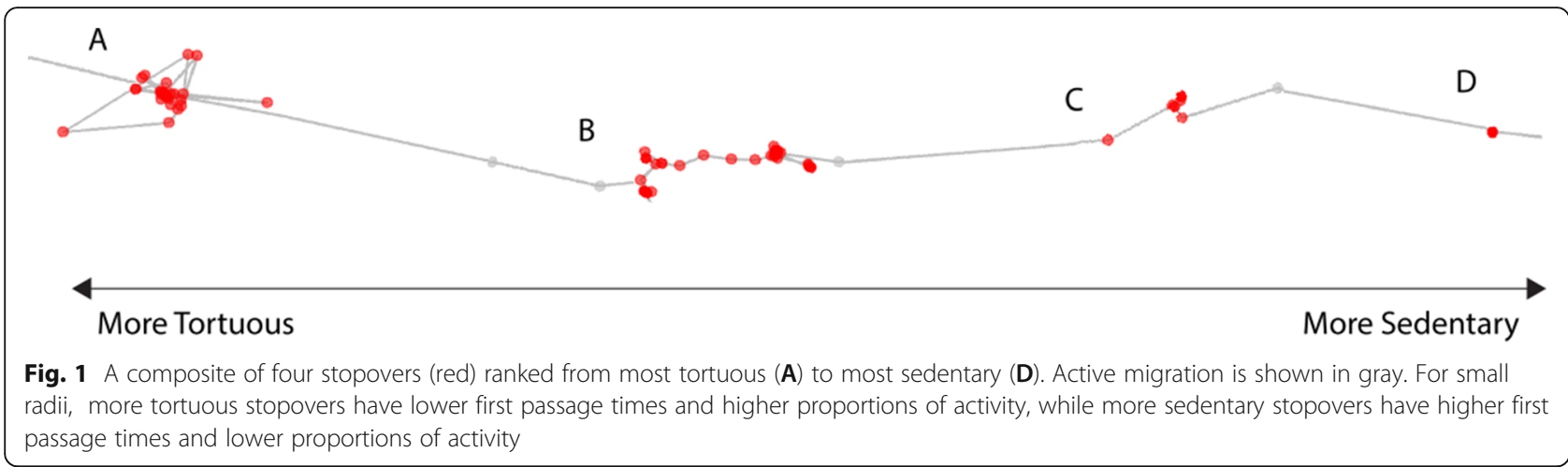

(Table 2). Proportion of activity during stopovers increased with mean thermal updraft velocity and mean temperature but decreased with mean precipitation fraction (Table 2).

\section{Discussion}

We found that Turkey Vultures frequently stopped actively migrating to avoid flying during poor weather conditions, adding to the growing literature recognizing weather avoidance as an important driver of stopover use by migrating birds [37-39]. Turkey Vultures ceased directed flight quickly in response to high rates of change in several weather variables and resumed migration when conditions improved. As obligate soaring birds, vultures are highly sensitive to changing weather conditions that affect the availability of updrafts. The variables they responded to are broadly associated with thermal updraft strength $[40,41]$, which is the most important type of updraft for these migratory populations [9]. The lack of response to orographic updraft velocity suggests that this was not an important updraft source for these populations, which largely avoid areas of high topographic relief along their migration routes.

Boundary layer, temperature, and thermal updraft velocity all follow a diurnal pattern [42] that may partly explain the close response to these variables by Turkey Vultures. The most frequent time for take-off for vultures to resume migration was in the morning. At early hours, there is rapid change in variables such as temperature and solar radiation, which lead to the development of thermals. Likewise, the most frequent time for the start of stopovers was in the afternoon when there is a slow decline in thermal strength and an increase in sensible heat flux [9]. The positive relationships between these variables and active migration is

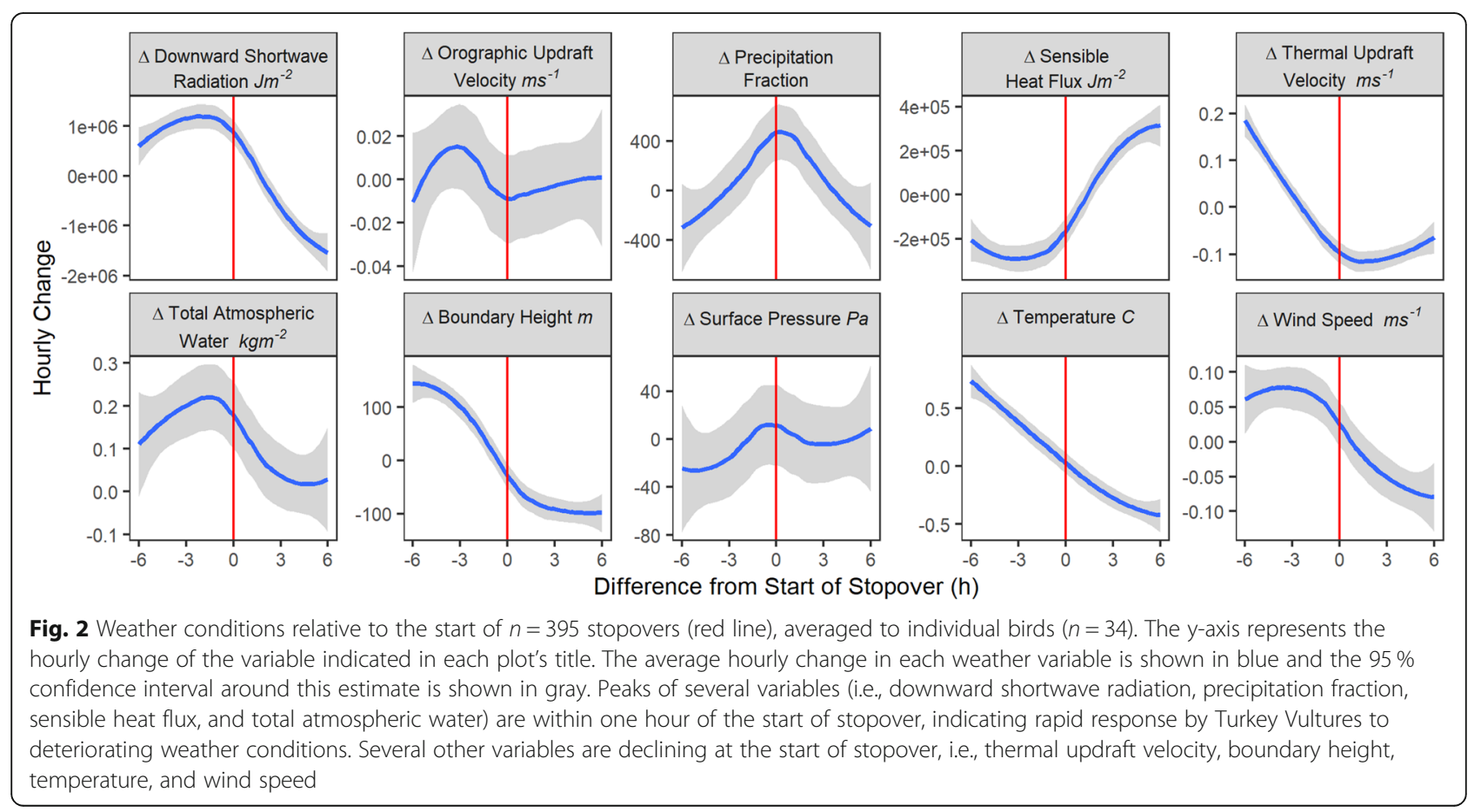



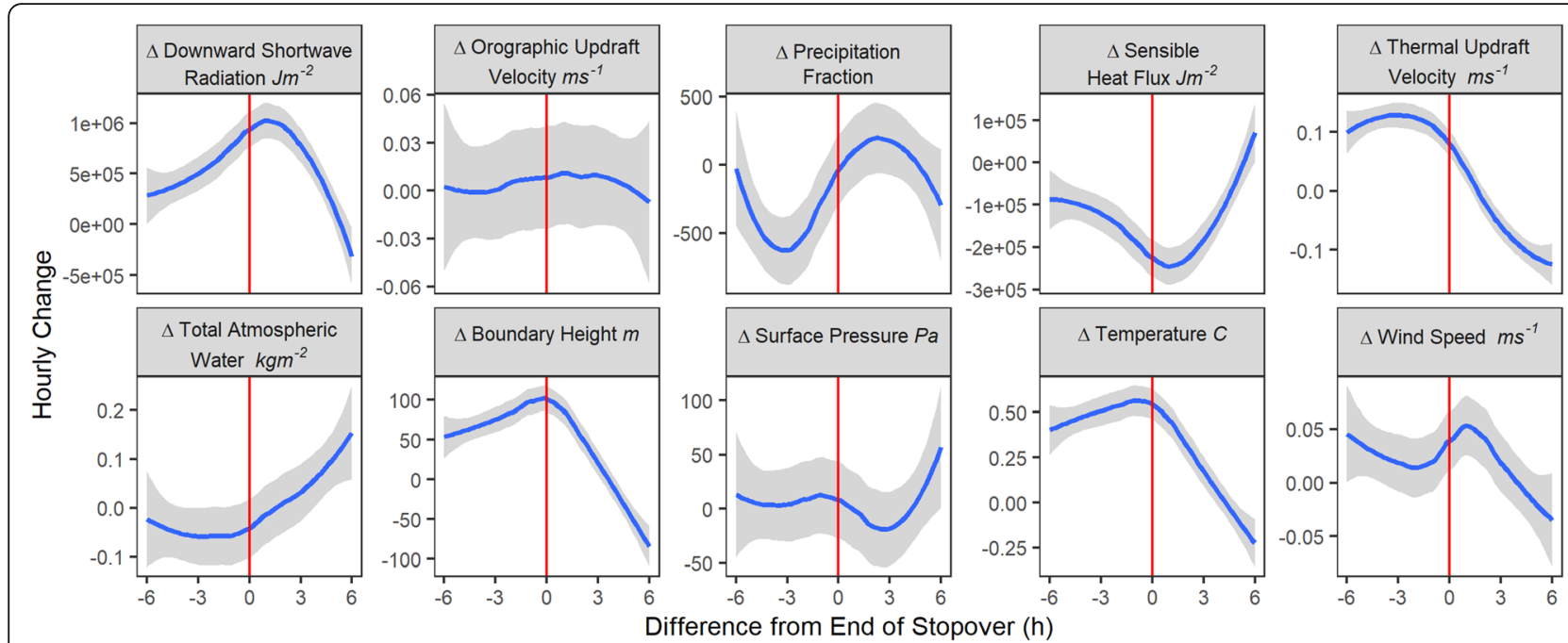

Fig. 3 Weather conditions relative to the end of $n=395$ stopovers (red line), averaged to individual birds ( $n=34$ ). The $y$-axis represents the hourly change of the variable indicated in each plot's title. The average hourly change in each weather variable is shown in blue and the $95 \%$ confidence interval around this estimate is shown in gray. Peaks of boundary height and temperature are within one hour of the end of stopover, and several other peaks are within three hours of the end of the stopover, indicating a response by Turkey Vultures to improving weather conditions

consistent with the behaviors of other soaring birds. Increased temperatures are associated with departure from staging sites by Bee-eaters Merops apiaster [43]. Boundary layer height is associated with faster migration speeds of Montagu's Harriers Circus pygargus and Honey Buzzards Pernis apivorus [20] and proportion of time spent soaring by Lesser Black-backed Gulls Larus fuscus [44]. Importantly, we found that the onset and cessation of stopovers by Turkey Vultures are associated with high rates of change in weather. The effect of the magnitude of change of each weather variable on the stopover behavior of vultures requires further study.

Increases in variables that do not fluctuate diurnally, such as precipitation, can disrupt updrafts and slow progress for some soaring migrants [20]. However, the onset

Table 2 Coefficients of the top generalized mixed-effects model (GLMM; binomial) using mean values of weather variables to predict the proportion of activity during stopovers (where a bird moved $>1 \mathrm{~km}$ per hour) by GPS-GSM tagged Turkey Vultures $(n=460)$. Individual $(n=34)$ nested within population $(n=4)$ was included as a random effect (both random effects: $S D=0.079$ ). Estimates reported here are of unscaled predictors

\begin{tabular}{llllc}
\hline Variable & $\boldsymbol{\beta}$ & $\mathrm{SE}$ & $\mathbf{z}$ & $\boldsymbol{p}$-value \\
\hline Intercept & -1.7332 & 0.1082 & -4.759 & $<0.001$ \\
Precipitation Fraction & -3.7785 & 0.1235 & -2.348 & 0.0189 \\
Thermal Updraft Velocity & 9.2448 & 0.1050 & 2.231 & 0.0257 \\
Temperature & 2.9703 & 0.1224 & 3.306 & $<0.001$ \\
\hline
\end{tabular}

and cessation of stopovers used by Turkey Vultures was not associated with wind speed. This finding echoes results for Ospreys Pandion haliaetus, which are also soaring migrants that frequently use stopovers: Ospreys' decisions to switch between active migration and stopover are not influenced by winds [45]. Another variable that we did not detect a response by Turkey Vultures to was surface air pressure. Although longer stopovers may have been associated with changes in surface air pressure, the time scale of our analyses was too fine to detect a response to changes in surface air pressure [43].

\section{Short stopovers}

Identifying stopovers at the daily scale may underestimate the duration of stopovers that are $>24 \mathrm{~h}$. For example, birds may actively migrate for several hours before stopping over and thereby exceed the distance threshold. The following day would be identified as the start of the stopover, several hours after the bird ceased directed flight. Half of the stopovers we identified did not meet the $<100 \mathrm{~km}$ and $>24 \mathrm{~h}$ criteria commonly used by other studies [16-22]. Only $4 \%$ of stopovers we identified started and ended during normal roosting hours (approx. 1700-0800 h), where the timing of movement activity would match with the normal flight activity patterns of diurnal migrants [46]. Stopovers identified at the daily scale, thus, would have incorrectly identified the start and end times for $96 \%$ of stopovers. As revealed by our results, birds are capable of responding rapidly to their environment; therefore, for studies 
interested in external drivers of stopover use, it is essential that stopovers be identified at fine temporal scales.

As identification of stopovers at the daily scale results in underestimates of stopover use, other soaring migrants may be shown to use short duration stopovers frequently. Several studies of migrating raptors only report results on stopovers $>24 \mathrm{~h}$ in duration, including: Swainson's Hawks Buteo swainsoni [16], Osprey [17, 18, 22], Black Kites Milvus migrans [19], Montagu's Harriers [20], Honey-buzzards [20, 21], Grey-faced Buzzards Butastur indicus [21], and Egyptian Vultures Neophron percnopterus [47, 48]. Given that half of the stopovers identified in our study were less than $24 \mathrm{~h}$, a reanalysis of stopover use at finer temporal scales is warranted.

Stopover use among migrants that forage en route is likely to be underestimated using existing definitions of stopovers. A migrant that is refueling may travel tens of kilometers in a day searching for food and would exceed these distance-based stopover thresholds even though they are not engaged in directed migratory flight. Several raptor species, including Montagu's Harriers [49], Ospreys [50] and Eleonora's Falcons Falco eleonorae [51], feed while migrating. Feeding en route results in lower daily migration distances [45] and in slower, more tortuous movements [51], but allows migrants to continue in the direction of their goal.

We found several stopovers where vultures were slow moving (see Fig. 1B) that suggest individuals were searching for food en route. However, these same stopovers could be the result of Turkey Vultures that are adverse to stopping, instead attempting to migrate while its progress was slowed by weak updrafts. Although Turkey Vultures are expected to complete most of their migrations while fasting [52], the relationship between movement activity during stopovers and weather conditions that promote the development of thermals also suggests not all stopovers are weather-related and some vultures do stop to feed during migration. The rates that stopovers are used for refueling versus weather-avoidance requires further study.

\section{Conclusions}

We sought to determine if stopover use by migrating Turkey Vultures was associated with changes in local weather conditions. We used a data-driven approach to identify short-duration stopovers $<24 \mathrm{~h}$, which are used as frequently as stopovers $>24 \mathrm{~h}$. The decision for Turkey Vultures to stop and resume active migration was in direct response to changes in several weather variables associated with thermal soaring, indicating that avoidance of poor weather conditions is a major function of stopover use by Turkey Vultures. Movement behavior during stopovers was typically driven by local weather conditions, where individuals moved more frequently during conditions that promote thermal updraft development, possibly in search of carrion. Whether or not such behavior occurs in other soaring migrants awaits additional study.

\section{Abbreviations}

FPT: First passage time; NDVI: Normalized difference vegetative index; GLMM: Generalized linear mixed model

\section{Supplementary Information}

The online version contains supplementary material available at https://doi. org/10.1186/s40462-021-00274-6.

Additional file 1: Supplemental Figure 1. Map of migrations by 34 individuals from four populations that represent three subspecies: Southwest USA (orange; C. aura aura), Central Canada (purple; C. aura meridionalis), Western Canada (dark green; C. aura meridionalis), and Southern South America (light green; C. aura ruficollis). White points indicate stopover locations $(n=589)$. Supplemental Figure 2. Histogram plots of the hours of the starts and ends of stopovers. Stopovers started most frequently around 1300-1500 h and ended most frequently around $1100 \mathrm{~h}$. Typical roosting times begin and end approximately at 1700 and $0800 \mathrm{~h}$, respectively. Due to some gaps in the data, some stopovers appeared to end during normal roosting hours (i.e., before $0700 \mathrm{~h}$ or after $1700 \mathrm{~h}$ ). Supplemental Figure 3. Average weather conditions for each individual, relative to the start of identified stopovers (red line), by population. The y-axis represents the hourly change of the variable indicated in each plot's title. Individuals in each population: (a) Southwest USA $n=14$, (b) Central Canada $n=9$, (c) Western Canada $n=6$, and (d) Southern South America $n=5$. Differences in responses across populations may be explained by unequal sample sizes, differing weather variable interactions associated with local climates, and stopovers used for feeding. Supplemental Figure 4. Average weather conditions for each individual, relative to the end of identified stopovers (red line), by population. The $y$-axis represents the hourly change of the variable indicated in each plot's title. Individuals in each population: (a) Southwest USA $n=14$, (b) Central Canada $n=9$, (c) Western Canada $n=$ 6 , (d) Southern South America $n=5$. Differences in responses across populations may be explained by unequal sample sizes, differing weather variable interactions associated with local climates, and stopovers used for feeding. Supplemental Table 1. Definitions of weather variables used and the rationale for including these variables. For variables that have units, units are provided in parentheses. Weather data were sourced from European Centre for Medium-Range Weather Forecasts (ECMWF) or Movebank. Supplemental Table 2. Linear mixed model summary of the number of stops per migration by population and season. Model was fit using Ime4 package version 1.1.23. Supplemental Table 3. Linear mixed model summary of the number of stops per migration by total migration distance. Model was fit using Ime4 package version 1.1.23.

\section{Acknowledgements}

This is Hawk Mountain conservation science contribution number 353. We thank Pascual López-López, Evan R. Buechley, Gerald S. Wilkinson, Derek A. Paley, and Christopher Rowe for their comments.

\section{Authors' contributions}

$J M M, K L B$, and WFF conceived of the project idea. KLB provided the data and JMM analyzed the data. JMM and WFF wrote the manuscript. All authors read and approved the final manuscript.

Authors' information

Not applicable 


\section{Funding}

JMM and WFF acknowledge support from NSF grant DBI1915347.

\section{Availability of data and materials}

The dataset supporting the conclusions of this article is available in the Zenodo repository, https://doi.org/10.5281/zenodo.4271905. The original dataset analyzed during the current study are available in the Movebank Data Repository, https://doi.org/10.5441/001/1.f3qt46r2 [30]

\section{Declarations}

\section{Ethics approval and consent to participate} Not applicable.

\section{Consent for publication}

Not applicable.

\section{Competing interests}

The authors declare no competing interests.

\section{Author details}

'Department of Biology, University of Maryland, College Park, MD 20742, USA. ${ }^{2}$ Hawk Mountain Sanctuary, Acopian Center for Conservation Learning, 410 Summer Valley Road, Orwigsburg, PA 17961, USA.

Received: 8 April 2021 Accepted: 27 June 2021

Published online: 10 July 2021

\section{References}

1. Richardson WJ. Timing and amount of bird migration in relation to weather: a review. Oikos. 1978:30:224-72.

2. Shamoun-Baranes J, Liechti F, Vansteelant WM. Atmospheric conditions create freeways, detours and tailbacks for migrating birds. J Comp Physiol A. 2017;203:509-29.

3. Smith AD, McWilliams SR. What to do when stopping over: behavioral decisions of a migrating songbird during stopover are dictated by initial change in their body condition and mediated by key environmental conditions. Behav Ecol. 2014;25:1423-35.

4. Matthews SN, Rodewald PG. Urban forest patches and stopover duration of migratory Swainson's thrushes. Condor. 2010;112:96-104.

5. Allen PE, Goodrich LJ, Bildstein KL. Within-and among-year effects of cold fronts on migrating raptors at Hawk Mountain, Pennsylvania, 1934-1991. Auk. 1996;113:329-38.

6. Inzunza ER, Hoffman SW, Goodrich LJ. Stopover ecology of neotropical migrants in central Veracruz, Mexico. In: Ralph JC, Rich TD, editors. Bird conservation implementation and integration in the Americas: proceedings of the third international partners in flight conference. Albany: US Department of Agriculture, Forest Service, Pacific Southwest Research Station 2005; p.657 - 72

7. Goodrich LJ. Stopover ecology of autumn-migrating raptors in the central Appalachians. The Pennsylvania State University, 2010.

8. Dodge S, Bohrer G, Bildstein K, Davidson SC, Weinzierl R, Bechard MJ, Barber $D$, Kays R, Brandes D, Han J. Environmental drivers of variability in the movement ecology of turkey vultures (Cathartes aura) in North and South America. Phil Trans R Soc B. 2014;369:20130195.

9. Bohrer G, Brandes D, Mandel JT, Bildstein KL, Miller TA, Lanzone M, Katzne T, Maisonneuve C, Tremblay JA. Estimating updraft velocity components over large spatial scales: Contrasting migration strategies of golden eagles and turkey vultures. Ecol Lett. 2012;15:96-103.

10. Mallon JM, Bildstein $\mathrm{KL}$, Katzner TE. In-flight turbulence benefits soaring birds. Auk. 2015;133:79-85.

11. Pennycuick CJ. Mechanics of flight. Avian Biology. London: Academic Press. 1975:5:1-75

12. Duerr AE, Miller TA, Lanzone M, Brandes D, Cooper J, O'Malley K, Maisonneuve C, Tremblay J, Katzner T. Testing an emerging paradigm in migration ecology shows surprising differences in efficiency between flight modes. PLoS One. 2012;7:e35548.

13. Kerlinger P. Flight strategies of migrating hawks. Chicago: University of Chicago Press; 1989
14. Spaar R, Bruderer B. Migration by flapping or soaring: Flight strategies of marsh, Montagu's and pallid harriers in southern Israel. Condor. 1997;99: 458-69.

15. Ferland-Raymond B, Bachand M, Thomas D, Bildstein K. Flapping rates of migrating and foraging turkey vultures Cathartes aura in Costa Rica. Vulture News. 2005:53:4-9.

16. Kochert MN, Fuller MR, Schueck LS, Bond L, Bechard MJ, Woodbridge B, Holroyd GL, Martell MS, Banasch U. Migration patterns, use of stopover areas, and austral summer movements of Swainson's hawks. Condor. 2011; 113:89-106.

17. Hake M, Kjellén N, Alerstam T. Satellite tracking of Swedish ospreys Pandion haliaetus: Autumn migration routes and orientation. J Avian Biol. 2001;32: 47-56.

18. Crawford RE, Long JA. Habitat preferences of juvenile Scottish ospreys Pandion haliaetus at stopover and wintering sites. Ring Migration. 2017; 2017(32):1-18

19. Sergio F, Tanferna A, De Stephanis R, Jiménez LL, Blas J, Hiraldo F. Migration by breeders and floaters of a long-lived raptor: Implications for recruitment and territory quality. Anim Behav. 2017:31:59-72

20. Vansteelant W, Bouten W, Klaassen R, Koks B, Schlaich A, Van Diermen J, Van Loon E, Shamoun-Baranes J. Regional and seasonal flight speeds of soaring migrants and the role of weather conditions at hourly and daily scales. J Avian Biol. 2015:46:25-39.

21. Shiu H-J, Tokita K-i, Morishita E, Hiraoka E, Wu Y, Nakamura H, Higuchi H. Route and site fidelity of two migratory raptors: grey-faced buzzards Butastur indicus and honey-buzzards Pernis apivorus. Ornithol Sci. 2006;5: $151-6$.

22. Monti F, Grémillet D, Sforzi A, Dominici JM, Bagur RT, Navarro AM, Fusani L, Klaassen RH, Alerstam T, Duriez O. Migration distance affects stopover use but not travel speed: Contrasting patterns between long-and short-distance migrating ospreys. J Avian Biol. 2018;49:e01839.

23. Ruxton GD, Houston DC. Obligate vertebrate scavengers must be large soaring fliers. J Theor Biol. 2004;228:431-6.

24. Rosser BW, George JC. Slow muscle fibres in the pectoralis of the turkey vulture. Zool Anz. 1986;217:252-8

25. Fauchald $P$, Tveraa T. Using first-passage time in the analysis of arearestricted search and habitat selection. Ecol. 2003;84:282-8.

26. Hatch DE. Energy conserving and heat dissipating mechanisms of the turkey vulture. Auk. 1970;87:111-24

27. Grilli MG, Lambertucci SA, Therrien J-F, Bildstein KL. Wing size but not wing shape is related to migratory behavior in a soaring bird. J Avian Biol. 2017; 48:669-78.

28. Efrat R, Hatzofe O, Nathan R. Landscape-dependent time versus energy optimizations in pelicans migrating through a large ecological barrier. Funct Ecol. 2019:33:2161-71.

29. Becciu P, Rotics S, Horvitz N, Kaatz M, Fiedler W, Zurell D, Flack A, Jeltsch F, Wikelski M, Nathan R, Sapir N. Causes and consequences of facultative sea crossing in a soaring migrant. Funct Ecol. 2020;34:840-52.

30. Bildstein KL, Barber D. Data from: inclement weather forces stopovers and prevents migratory progress for obligate soaring migrants. Movebank Data Repos. 2021. https://doi.org/10.5441/001/1.f3qt46r2.

31. Dodge S, Bohrer G, Weinzierl R, Davidson SC, Kays R, Douglas D, Cruz S, Han J, Brandes D, Wikelski M. The environmental-data automated track annotation (Env-data) system: linking animal tracks with environmental data. Move Ecol. 2013:1:3.

32. Calenge $C$. The package adehabitat for the $R$ software: Tool for the analysis of space and habitat use by animals. Ecol Modell. 2006;197:1035.

33. Hurme E, Gurarie E, Greif S, Flores-Martínez JJ, Wilkinson GS, Yovel Y. Acoustic evaluation of behavioral states predicted from GPS tracking: a case study of a marine fishing bat. Mov Ecol. 2019;7:21.

34. Le Corre M, Dussault C, Côté SD. Detecting changes in the annual movements of terrestrial migratory species: using the first-passage time to document the spring migration of caribou. Mov Ecol. 2014;2:19.

35. Sommerfeld J, Kato A, Ropert-Coudert Y, Garthe S, Hindell MA. Foraging Parameters Influencing the Detection and Interpretation of Area-Restricted Search Behaviour in Marine Predators: A Case Study with the Masked Booby. PLOS ONE. 2013;8:e63742.

36. R Core Team. R: A language and environment for statistical computing. R Foundation for Statistical Computing, Vienna, Austria. 2020.

37. Calvert AM, Taylor PD, Walde S. Cross-scale environmental influences on migratory stopover behaviour. Glob Change Biol. 2009;15:744-59. 
38. Arizaga J, Mendiburu A, Andueza M, Fontanilles P, Fourcade J-M, UrbinaTobias $P$. Deteriorating weather conditions predict the use of suboptimal stopover sites by aquatic warblers Acrocephalus paludicola. Acta Ornithol. 2011:46:202-6.

39. Clipp HL, Cohen EB, Smolinsky JA, Horton KG, Farnsworth A, Buler JJ. Broadscale weather patterns encountered during flight influence landbird stopover distributions. Remote Sens. 2020;12:565.

40. Poessel SA, Brandt J, Miller TA, Katzner TE. Meteorological and environmental variables affect flight behaviour and decision-making of an obligate soaring bird, the California condor Gymnogyps californianus. Ibis. 2018;160:36-53.

41. Duerr AE, Miller TA, Lanzone M, Brandes D, Cooper J, O'Malley K, Maisonneuve C, Tremblay JA, Katzner T. Flight response of slope-soaring birds to seasonal variation in thermal generation. Funct Ecol. 2015;29:77990.

42. Stull RB. An introduction to boundary layer meteorology. Boston: Kluwer Academic Publishers; Springer 1988.

43. Sapir N, Wikelski M, Avissar R, Nathan R. Timing and flight mode of departure in migrating European bee-eaters in relation to multi-scale meteorological processes. Behav Ecol Sociobiol. 2011;65:1353-65.

44. Shamoun-Baranes J, Bouten W, van Loon EE, Meijer C, Camphuysen CJ. Flap or soar? How a flight generalist responds to its aerial environment. Phil Trans R Soc B. 2016;371:20150395.

45. Thorup K, Alerstam T, Hake M, Kjellén N. Traveling or stopping of migrating birds in relation to wind: An illustration for the osprey. Behav Ecol. 2006;17: 497-502.

46. Mallon JM, Tucker MA, Beard A, Bierregard RO Jr, Bildstein KL, BöhningGaese K, Brzorad JN, Buechley ER, Bustamante J, Carrapato C, et al. Diurnal timing of nonmigratory movement by birds: the importance of foraging spatial scales. J Avian Biol. 2020;51:e02612

47. López-López P, García-Ripollés C, Urios V. Individual repeatability in timing and spatial flexibility of migration routes of trans-Saharan migratory raptors. Curr Zool. 2014;60:642-52.

48. Buechley ER, Oppel S, Beatty WS, Nikolov SC, Dobrev V, Arkumarev V, Saravia V, Bougain C, Bounas A, Kret E. others. Identifying critical migratory bottlenecks and high-use areas for an endangered migratory soaring bird across three continents. J Avian Biol. 2018;49:e01629.

49. Klaassen RH, Schlaich AE, Bouten W, Koks BJ. Migrating Montagu's harriers frequently interrupt daily flights in both Europe and Africa. J Avian Biol. 2017;48:180-90

50. Strandberg R, Alerstam T. The strategy of fly-and-forage migration, illustrated for the osprey (Pandion haliaetus). Behav Ecol Sociobiol. 2007;61: 1865-75.

51. Mellone U, López-López P, Limiñana R, Piasevoli G, Urios V. The transequatorial loop migration system of Eleonora's falcon: differences in migration patterns between age classes, regions and seasons. J Avian Biol. 2013;44:417-26.

52. Bildstein KL. Migrating raptors of the world: their ecology \& conservation. Ithaca: Cornell University Press; 2006.

\section{Publisher's Note}

Springer Nature remains neutral with regard to jurisdictional claims in published maps and institutional affiliations.

Ready to submit your research? Choose BMC and benefit from:

- fast, convenient online submission

- thorough peer review by experienced researchers in your field

- rapid publication on acceptance

- support for research data, including large and complex data types

- gold Open Access which fosters wider collaboration and increased citations

- maximum visibility for your research: over $100 \mathrm{M}$ website views per year

At $\mathrm{BMC}$, research is always in progress.

Learn more biomedcentral.com/submissions 